\title{
Red cell distribution width and mean platelet volume in patients with irritable bowel syndrome
}

\author{
Gulali Aktas ${ }^{1}$, Aytekin Alcelik ${ }^{1}$, Buket Kin Tekce ${ }^{2}$, Vildan Tekelioglu${ }^{1}$, Mustafa Sit ${ }^{3}$, Haluk Savli ${ }^{1}$ \\ ${ }^{1}$ Department of Internal Medicine, Abant Izzet Baysal University Hospital, Bolu, Turkey \\ 2Department of Biochemistry, Abant Izzet Baysal University Hospital, Bolu, Turkey \\ ${ }^{3}$ Department of General Surgery, Abant Izzet Baysal University Hospital, Bolu, Turkey
}

Prz Gastroenterol 2014; 9 (3): 160-163

DOI: $10.5114 /$ pg.2014.43578

Key words: irritable bowel syndrome, mean platelet volume, red cell distribution width, inflammation.

Address for correspondence: Gulali Aktas MD, Department of Internal Medicine, Abant Izzet Baysal University Hospital, Bolu, Turkey, phone: +3742534656, fax: +3742534615, e-mail: draliaktas@yahoo.com

\begin{abstract}
Introduction: Possible pathophysiological mechanisms of irritable bowel syndrome (IBS) are interactions between microbial flora of the gut and the mucosal/systemic immune system, post-infectious status and inflammation. Mean platelet volume (MPV) and red cell distribution width (RDW) have been reported as inflammatory markers in patients with inflammatory bowel disease, but they have not been studied in functional gastrointestinal disorders.

Aim: To investigate whether there was an association between haemogram parameters (RDW and MPV) and IBS.

Material and methods: Forty patients with IBS and 44 healthy controls were included to this retrospective study. Patients diagnosed with IBS according to Rome III criteria were included as the IBS group. They were all screened for psychiatric or organic bowel diseases for the sake of precise diagnosis.

Results: Both RDW $(p<0.001)$ and MPV $(p=0.046)$ were increased in patients with IBS compared to controls. This increase in RDW and MPV was independent of the type of IBS.

Conclusions: The RDW and MPV should be laboratory indicators of IBS. More prospective studies with larger cohorts are needed to confirm our results.
\end{abstract}

\section{Introduction}

Irritable bowel syndrome (IBS) is a functional disorder of the gastrointestinal system, which is characterized by alteration in bowel habits, chronic abdominal pain, discomfort and bloating. The prevalence of IBS is estimated about $12-30 \%$, worldwide [1-3]. Functional gastrointestinal disorders are associated with significant impairment of quality of life and considerable economic burden on healthcare systems $[4,5]$. Possible underlying pathophysiological mechanisms of IBS are interactions between microbial flora of the gut and mucosal/systemic immune system, post-infectious status and inflammation [6-9]. We still do not know much about the systemic effects of the subclinical inflammation in IBS.

In addition to platelets' role in homeostasis and tissue repairing [10], it is now understood that platelets play an important role in diseases associated with inflammation. Activated platelets are involved in the inflammatory processes of various disorders [11-14]. A widely used marker of platelet function is mean platelet volume (MPV), which reflects the production rate in bone marrow and activation of platelets [15]. The MPV has been studied in inflammatory diseases of the bowel $[16,17]$, but, to our knowledge, it has not yet been studied in functional gastrointestinal disorders.

Red cell distribution width (RDW) reflects the dimension variability of red blood cells. As well as anaemia, an increase in RDW has been reported in literature in various other diseases [18-20]. Similar to MPV, RDW has also been reported as an inflammatory marker in patients with inflammatory bowel disease [21-25], but it has not been studied in functional gastrointestinal disorders.

\section{Aim}

To the best of our knowledge, there are no reports in the literature about the haemogram parameters of IBS 
patients. Therefore, in this retrospective study, we aimed to investigate whether there was an association between haemogram parameters (RDW and MPV) and IBS.

\section{Material and methods}

Forty patients with IBS and 44 healthy controls were included in this retrospective study. Patients diagnosed with IBS according to Rome III criteria were included as the IBS group. They were all screened for psychiatric or organic bowel diseases for the sake of precise diagnosis. Control group was consisted of healthy subjects who have been evaluated in our outpatient clinics for a routine check up. None of the subjects in the study and control groups had a history of use of medications that might have affected platelet function (e.g. aspirin). Individuals with a history of major surgery in the previous 5 years, diabetes mellitus, infectious diseases and chronic inflammatory diseases were excluded. Patients diagnosed with IBS were classified as either constipation or diarrhoea and mixed type.

Venous blood samples were obtained and put into sterile standard tubes containing a constant amount of anticoagulant. Laboratory tests were carried out within several minutes after the blood samples were obtained. The complete blood count analyses were performed on an LH 780 automatic analyser from Beckman Coulter (Beckman Coulter In.; Bre CA). Original kits from the manufacturer were used in laboratory analyses.

White blood cell count (WBC), haemoglobin (Hgb), haematocrit (Htc), mean corpuscular volume (MCV), RDW, platelet count (PLT) and MPV values of the study population were obtained from the computerised medical database of our hospital.

\section{Statistical analysis}

Data was assessed using SPSS software. (SPSS 15.0; SPSS Inc., Chicago, IL, USA). Results are expressed as mean \pm SD. Variables are conducted with independent samples $t$ test and Mann- Whitney $U$ test. A $p$ value $<0.05$ was considered as statistically significant. The study is approved by the local ethics committee of Abant Izzet Baysal University School of Medicine.

\section{Results}

The IBS group consisted of 13 male and 27 female patients, while the control group consisted of 18 male and 26 female subjects. The difference was not statistically significant $(p=0.42)$.

The mean ages of the IBS and control groups were $42.2 \pm 15.2$ and $39.3 \pm 10.8$ years, respectively. The difference was not statistically significant $(p=0.32)$. The WBC $(p=0.53), \mathrm{Hgb}(p=0.33)$, Htc $(p=0.21)$, MCV $(p=0.84)$ and platelet $(p=0.97)$ levels were not significantly different between IBS and control groups.

Mean RDW of the IBS and control groups were 16.53 \pm 0.37 and $16.06 \pm 0.61$, respectively. The difference was statistically significant $(p<0.001)$. Similar to RDW, MPV was significantly increased in the study group (8.27 $\pm 1.07)$ compared to controls $(7.80 \pm 1.01)(p=0.046)$. Table I shows the laboratory data of the groups.

We compared the general characteristics and laboratory data of the IBS group by the type of IBS, either constipation or diarrhoea and mixed types. Twenty-seven IBS patients were grouped as constipation type and 13 as diarrhoea and mixed type. There were 20 female and 7 male patients in the constipation group, and 7 female and 6 male patients in the diarrhoea and mixed type IBS groups. The difference was not statistically significant $(p=0.20)$. Furthermore, mean age $(p=0.187)$, WBC $(p=0.367)$, Hgb $(p=0.622), \operatorname{Htc}(p=0.482), \operatorname{MCV}(p=0.083)$, platelet $(p=0.526), \operatorname{RDW}(p=0.155)$ and MPV $(p=0.143)$ were not statistically significantly different between these groups. Table II shows the general characteristics and laboratory data of the constipation, and the diarrhoea and mixed type IBS groups.

\section{Discussion}

We found that RDW and MPV were increased in patients with IBS compared to controls. Moreover, this

Table I. Laboratory data of the groups

\begin{tabular}{lccc} 
Data & IBS group & Control group & Value of $\boldsymbol{p}$ \\
\hline WBC $\left[\times 10^{\%} / \mathrm{ml}\right]$ & $6.54 \pm 1.51$ & $6.76 \pm 1.7$ & 0.53 \\
\hline $\mathrm{Hgb}[\mathrm{g} / \mathrm{l}]$ & $139.5 \pm 11.1$ & $141.8 \pm 10.3$ & 0.33 \\
\hline $\mathrm{Htc}[\%]$ & $40.86 \pm 2.77$ & $41.61 \pm 2.71$ & 0.21 \\
\hline $\mathrm{MCV}[\mathrm{fl}]$ & $87.48 \pm 4.59$ & $87.29 \pm 4.36$ & 0.84 \\
\hline RDW & $0.165 \pm 0.0037$ & $0.160 \pm 0.006$ & $<0.001$ \\
\hline $\mathrm{PLT}\left[\times 10^{9} / \mathrm{ml}\right]$ & $260 \pm 65$ & $260 \pm 59$ & 0.97 \\
\hline MPV $[\mathrm{fl}]$ & $8.27 \pm 1.07$ & $7.80 \pm 1.01$ & 0.046
\end{tabular}

WBC - white blood cell count, Hgb - haemoglobin, Htc - haematocrit, MCV - mean corpuscular volume, RDW - red cell distribution width, PLT - platelet count, MPV- mean platelet volume 
Table II. General characteristics and laboratory data of constipation, and diarrhoea and mixed-type IBS groups

\begin{tabular}{llccc} 
Parameter & & Constipation type IBS group & $\begin{array}{c}\text { Diarrhoea and mixed type } \\
\text { IBS group }\end{array}$ & Value of $p$ \\
\hline Age $[$ years] & & $40 \pm 16$ & $46 \pm 11$ & 0.187 \\
\hline Gender & Female & 20 & 7 & 0.20 \\
\cline { 2 - 4 } & Male & 7 & 6 & 0.367 \\
\hline WBC $\left[\times 10^{9} / \mathrm{ml}\right]$ & $6.39 \pm 1.48$ & $6.85 \pm 1.6$ & 0.622 \\
\hline Hgb $[\mathrm{g} / \mathrm{dl}]$ & $138.9 \pm 12$ & $140.8 \pm 9.2$ & 0.482 \\
\hline Htc $[\%]$ & $40.64 \pm 2.93$ & $41.31 \pm 2.47$ & 0.083 \\
\hline MCV $[\mathrm{fl}]$ & $86.42 \pm 3.5$ & $89.67 \pm 5.84$ & 0.155 \\
\hline RDW & $0.166 \pm 0.0043$ & $0.164 \pm 0.002$ & 0.526 \\
\hline PLT $\left[\times 10^{9} / \mathrm{ml}\right]$ & $255 \pm 62$ & $269 \pm 72$ & 0.143
\end{tabular}

increase in RDW and MPV was independent of the type of IBS. There is no laboratory parameter defined in the diagnosis of IBS. Therefore, we think that the results of our study are important because of the strong association between RDW, MPV and IBS.

The difference in RDW and MPV between study and control groups was independent from the type of IBS. Because, MPV and RDW were not significantly different between constipation or diarrhoea types in IBS subgroup.

The RDW and MPV have been analysed in recent studies. Song et al. reported that RDW was associated with disease severity in patients with inflammatory bowel disease [24]. However, as well as increased RDW values, patients with moderate to severe active disease had significantly reduced $\mathrm{Hgb}$ and $\mathrm{Htc}$ values compared to patients on remission, in their report. Moreover, Cakal et al. found that elevation in RDW was more common in patients with active inflammatory bowel disease compared to healthy controls [21]. However, Hgb and Htc levels were statistically significantly reduced in patients with active inflammatory bowel disease compared to controls, in that study. It has been reported by Arhan et al. that RDW and MPV were increased in patients with inflammatory bowel diseases compared to healthy subjects [25]. As well as RDW and MPV, the study group had statistically significantly differences in WBC, Hgb, Htc and MCV values compared to the control group in that report. Anaemia, especially due to iron deficiency, may cause an increase in RDW in these studies. However, there was no statistically significant difference between study and control groups in terms of Hgb, Htc, MCV, PLT and WBC levels in our results.

In a recent study, elevated RDW levels in patients with IBS, Crohn's disease and ulcerative colitis were reported at $8.3 \%, 63.3 \%$ and $45.7 \%$, respectively [23].
The authors considered normal values of RDW to be between $11 \%$ and $14 \%$. They found RDW elevation was less common in patients with IBS compared to Crohn's disease and ulcerative colitis, but, there is no data in their report about concomitant diseases, laboratory parameters other than RDW (e.g. Hgb, Htc, WBC) or the use of medications that might affect blood count analyses. None of the individuals in our study had concomitant diseases or a recent history of use of medications that might have affected the results of blood count analyses.

Some authors speculate that subclinical inflammation may play a role in IBS pathogenesis $[6-8,26]$. Thus, our results were not surprising, because RDW and MPV have been reported to increase in inflammatory diseases.

The limitations of the present study are its retrospective design and relatively small study population.

\section{Conclusions}

The RDW and MPV should be laboratory indicators of IBS in the absence of potential confounders, such as; anaemia, infection and inflammation. More prospective studies with larger cohorts are needed to confirm our results.

\section{References}

1. Agréus L, Svärdsudd K, Nyrén O, Tibblin G. Irritable bowel-syndrome and dyspepsia in the general-population - overlap and lack of stability over time. Gastroenterology 1995; 109: 671-80.

2. Kennedy TM, Jones RH, Hungin AP, et al. Irritable bowel syndrome, gastro-oesophageal reflux, and bronchial hyper-responsiveness in the general population. Gut 1998; 43: 770-4.

3. Hungin AP, Whorwell PJ, Tack J, Mearin F. The prevalence, patterns and impact of irritable bowel syndrome: an international survey of 40,000 subjects. Aliment Pharmacol Ther 2003; 17: 643-50 
4. Koloski NA, Talley NJ, Boyce PM. The impact of functional gastrointestinal disorders on quality of life. Am J Gastroentero 2000; 95: 67-71.

5. Drossman DA, Dumitrascu DL. Rome III: New standard for functional gastrointestinal disorders. J Gastrointestin Liver Dis 2006; 15: 237-41.

6. Guarner F, Malagelada JR. Gut flora in health and disease. Lancet 2003; 361: 512-9.

7. Spiller RC. Postinfectious irritable bowel syndrome. Gastroen terology 2003; 124: 1662-71.

8. Törnblom H, Lindberg G, Nyberg B, Veress B. Full-thickness biopsy of the jejunum reveals inflammation and enteric neuropathy in irritable bowel syndrome. Gastroenterology 2002; 123: 1972-9.

9. Camilleri M, Katzka DA. Irritable bowel syndrome: methods, mechanisms, and pathophysiology. Genetic epidemiology and pharmacogenetics in irritable bowel syndrome. Am J Physiol Gastrointest Liver Physiol 2012; 302: G1075-84.

10. Polińska B, Matowicka-Karna J, Kemona H. Assessment of the influence of the inflammatory process on the activation of blood platelets and morphological parameters in patients with ulcerative colitis (colitis ulcerosa). Folia Histochem Cytobiol 2011; 49: 119-24.

11. Grove EL, Hvas AM, Kristensen SD. Immature platelets in patients with acute coronary syndromes. Thromb Haemost 2009 101: 151-6.

12. Ranjith MP, Divya R, Mehta VK, et al. Significance of platelet volume indices and platelet count in ischaemic heart disease. J Clin Pathol 2009; 62: 830-3.

13. Fajardo LF, Rao S. Platelet enlargement in malaria. Mil Med 1971; 136: 463-4.

14. Varma N, Naseem S. Hematologic changes in visceral leishmaniasis/kala azar. Indian J Hematol Blood Transfus 2010; 26 78-82.

15 . Briggs C. Quality counts: new parameters in blood cell counting. Int J Lab Hematol 2009; 31: 277-97.

16. Kapsoritakis AN, Koukourakis MI, Sfiridaki A, et al. Mean platelet volume: a useful marker of inflammatory bowel disease activity. Am J Gastroenterol 2001; 96: 776-81.

17. Järemo P, Sandberg-Gertzen H. Platelet density and size in inflammatory bowel disease. Thromb Haemost 1996; 75: 560-1.

18. Anderson JL, Ronnow BS, Horne BD, et al. Usefulness of a complete blood count-derived risk score to predict incident mortality in patients with suspected cardiovascular disease. Am J Cardiol 2007; 99: 169-74.

19. Ani C, Ovbiagele B. Elevated red blood cell distribution width predicts mortality in persons with known stroke. J Neurol Sci 2009; 277: 103-8.

20. Brusco G, Di Stefano M, Corazza GR. Increased red cell distribution width and coeliac disease. Dig Liver Dis 2000; 32: 128-30.

21. Cakal B, Akoz AG, Ustundag Y, et al. Red cell distribution width for assessment of activity of inflammatory bowel disease. Dig Dis Sci 2009; 54: 842-7.

22. Clarke K, Sagunarthy R, Kansal S. RDW as an additional marker in inflammatory bowel disease/undifferentiated colitis. Dig Dis Sci 2008; 53: 2521-3.

23. Farkas K, Papp M, Nyári T, et al. Red blood cell distribution width in combination with serological markers can help in the differentiation between Crohn's disease and ulcerative colitis. Open Gastroenterol J 2010; 4: 1-4.

24. Song CS, Park DI, Yoon MY, et al. Association between red cell distribution width and disease activity in patients with inflammatory bowel disease. Dig Dis Sci 2012; 57: 1033-8.

25. Arhan M, Onal IK, Tas A, et al. The role of red cell distribution width as a marker in inflammatory bowel disease. Turk J Med Sci 2011; 41: 227-34.

26. Camilleri M, Lasch K, Zhou W. Irritable bowel syndrome: methods, mechanisms, and pathophysiology. The confluence of increased permeability, inflammation, and pain in irritable bowel syndrome. Am J Physiol Gastrointest Liver Physiol 2012; 303: G775-85.

Received: 15.07 .2013

Accepted: 24.12 .2013 